\title{
SUPPORT FOR MANAGING PARTLY CONFIGURABLE MODULAR SYSTEMS
}

\author{
Pakkanen, Jarkko (1); \\ Heikkinen, Teuvo (2); \\ Adlin, Nillo (1); \\ Lehtonen, Timo (1); \\ Mämmelä, Janne (3); \\ Juuti, Tero (1) \\ 1: Tampere University; \\ 2: Konecranes Oyj; \\ 3: University of Oulu
}

\begin{abstract}
The paper studies what kind of support could be applied to the management of partly configurable modular systems. The main tasks of product management, product portfolio management and product variety management are defined. In addition, a partly configurable product structure and modular system are defined. Because the limited support in the literature for managing partly configurable modular systems, the article reviews previous product development cases in which authors have been involved on lessons learnt basis, i.e., if the methods and tools used in the cases could provide support for the research objective. As a result, the existing definition of the modular system should be extended by the concepts of non-module and design decision sequence description when dealing with partly configurable modular systems. This is because engineer-to-order should be made possible in cases where it brings clear added value to the customer compared to completely pre-defined solutions that may limit the customer's interest in the offering. Tools to assess the impact of changes to the product offering are required. These should be taken into account in frameworks that are used in method and tool development.
\end{abstract}

Keywords: Modularisation, Product architecture, Product variety management, Product structuring, Portfolio management

\section{Contact:}

Pakkanen, Jarkko Tapani

Tampere University of Technology

Mechanical Engineering and Industrial Systems

Finland

jarkko.pakkanen@tut.fi 


\section{INTRODUCTION}

The development and management of customisable products is usually based on modularisation, the development of product platforms and families, and product configuration. Modularisation and configuration based on standard and predefined elements is well known in the literature, but when the product also includes partitions to be developed on a delivery-specific engineering basis limited support exists. Central to modularisation is the development of a product variety that adapts to different customer requirements so that different product variants contain commonality (Andreasen, 2011). Modularity has been utilised and studied in many different industries, such as mobile work machines (Bruun et al., 2013), power tools (Cai et al., 2009), motors (Sosa et al., 2007), cars (Fujimoto, 2007; Winterkorn and Pötsch, 2012), furniture (Kazemzadeh et al., 2008), and satellites (Borgue et al., 2019). Product platforms and product families are also linked to customisable products. According to Meyer and Lehnerd (1997), a product platform is a set of subsystems and interfaces that form a common structure from which a stream of derivative products can be efficiently developed and produced. They presented the famous examples of Hewlett Packard's printers and Black \& Decker's line of power tools. Later, the concept of platform has been described in different ways. Kristjansson et al. (2004) made a literature review of platform definitions and concluded that a platform is a collection of core assets that are reused to achieve a competitive advantage. There are also many definitions of product families. According to Lehtonen et al. (2003), a product platform enables launching a product family that consists of modules developed in the platform development level and that corresponds to certain market needs now and in predictable future.

Product configuration is usually associated with either the engineering or sales phase. For example, Brown (1998) states that configuring includes the selecting of components, establishing abstract and specific relationships between components and the testing of compatibility and goal satisfaction. A configurable product can be understood as a product family based on pre-designed elements such as modules (Tiihonen et al., 1999). Challenges have been identified in the product development projects of companies in the manufacturing industry, which have led to consideration of how to manage partly configurable modular systems, what kind of knowledge those consists of and what features those have. Partly configurable means that the architecture of the product range includes also possibility for customer specific elements (Juuti, 2008). Juuti's (2008) definition of partly configurability has similarities with Pahl and Beitz's (2013) description of the differences between a mixed system and a modular system. According to them, the mixed system differs from the modular system in that the former also includes customer-specific functions that cannot be foreseen in advance. In this article, however, we use the term modular system instead of mixed system, but consider one-off solutions with a partly configurable prefix. By system in this context we mean a set of products such as a product family. One of the essential challenges identified is the management of the modular product range during its life cycle, especially when the product range is under pressures to change. It is important to understand how, for example, the identification of the effects of change could be supported. Therefore, in order to further investigate this issue, this study seeks an answer to the following research question (RQ):

- $\quad$ RQ. How to support managing partly configurable modular systems?

We seek an answer to this question by reviewing our previous research cases and publications retrospectively. Thus, the cases we have selected constitute the most important research data in the article. In the next section, Section 2, we study relevant literature to our RQ. Section 3 includes description of the research approach. Section 4 focuses on analysing previous product development projects in which authors have participated as researchers or supervisors. On the basis of lessons learnt in the selected case studies, potential support that could be useful in managing partly configurable modular systems is discussed. Section 5 presents discussion and the paper is concluded in Section 6.

\section{LITERATURE}

This section reviews the key topics related to the RQ. First, product management is explained, followed by a partly configurable product structure and modular system definitions. 


\subsection{Product management}

According to Roach (2011), product management tasks includes internal and external product monitoring, product budgeting, forecasting, and communication and coordination tasks. The list is further strengthened by core activities of product management, creating vision, product lifecycle management, and collaboration with internal and external stakeholders by Maglyas et al. (2012). Vähäniitty (2003) further extends with portfolio management, organisation, and quality strategy. Roach (2011) concludes that there is a wide range of "boundary-spanning" activities, both internal and external, that product management consists of. Gorchels (2003) findings are aligned, where product manager coordinates with various functions of a business. Murphy and Gorchels (1996) explain that product managers rely on many functional areas of the company for decision making, such as sales, research and development, production, marketing research, product service, and advertising - and moderately with distribution, warehousing and finance functions. These findings suggest further investigation towards management activities of product management due to the function's inherently complex operating environment. Murphy and Gorchels (1996) explain that advantages of product management are for the greater success of the offering, but also customer loyalty due to collective offering base of the firm; providing also healthy internal competitive environment and promotion opportunities to higher management levels. Product management tasks can be approached through the role of product manager, and the reflective decision-making on which product manager has an effect on. Product, such as product development and modifications, decisions on packaging, and on product recalls. Promotion, such as trade shows and exhibits, and sales promotion. Sales, such as product trainings for sales, technical support, and approvals of special requests. Pricing, such as setting as base prices or determining discounts. Research and strategy, such as developing marketing plans, long range planning, business analysis and expected customer service levels. (Murphy and Gorchels, 1996).

\subsection{Product portfolio management and product variety management}

Enabling a wide range of products competitively for customers poses challenges for management (Forza and Salvador, 2008). Product portfolio management and product variety management are often referred to in overlapping definitions. Tolonen et al. (2015) present that product portfolio can consists of hardware, software, services and documentation types of products a company offers. They explain that products of a portfolio can be classified in many ways such as by customer segments or product families. The often used definition of a product variety is narrower describing the range of products the company can offer within a particular period of time in response to market demand (Ulrich and Eppinger, 2008). Product portfolio management refers to a dynamic decision-making process of evaluating, selecting, prioritising, and allocating resources to product development projects with the goal of maximising the value of portfolio, hence return on R\&D spending (Cooper et al., 2001; McNally et al., 2009). Jugend and Da Silva (2014) present that several practices are related to product portfolio management from methodological, organisational and strategic viewpoint. As a detailed example, Ulonska and Welo (2014) highlight explicit and visual knowledge representations for product variant discovery and structuring. Visual knowledge representations relate to design rationale modelling. Clear design rationale supports reusability and creation of product structures, from where the designs are then transferable to supply chain (Gedell and Johannesson, 2013). Several strategies, techniques, tools, and enablers are connected to product variety management in design, planning and manufacturing stages relating to parts, products, enterprise, and market (ElMaraghy et al., 2013; Um et al., 2017). The range of strategies included in these perspectives is wide, including, for example, design for variety tactics such as focusing on product architecture and modularisation. ElMaraghy et al. (2013) connect modular architecture and configuration by allowing customers to select pre-planned and pre-designed product features and options using a configurator. They also explain that customisation is based on pre-defined options whereas personalisation enables making true unique product. Despite the fact that the management topics have been extensively discussed in previous research, the partly configurable modular system is hardly addressed. The following subsections describe in more detail what partly configurable and modular products are.

\subsection{Partly configurable products}

Juuti and Lehtonen (2006) describe that partly configurable product structure includes standard parts, configurable parts and one-of-a-kind parts. They discuss that commonality is based on reusing specific 
elements and variety is achieved by reusing a particular combination of standard and modular parts by configuring, or by delivery specific engineering. According to Haug (2008), configuring means combining predefined entities (physical or non-physical) and defining their variable properties while adhering to constraints and compatible interface combinations in a way that fulfils given requirements. Pulkkinen (2007) explains that configurable products include a pre-designed general product structure that has been designed to meet a given range of specific requirements. Tiihonen et al. (1999) continue explaining that the sales-delivery process requires only systematic variant design, not adaptive or original design. Thus, partly configurable products enable engineering-to-order (ETO) and unique solutions in specific sections of a product while simultaneously obeying constraints of architectural and interface decisions and following beneficial design rules.

\subsection{Modular systems}

Pahl and Beitz (2013) define that modular products fulfil various overall functions by combining distinct building blocks or modules. They have defined a modular system as a possible collection of different modules. Pakkanen et al. $(2016,2019)$ make this definition broader by stating that partitioning logic, architecture, interfaces, set of modules and configuration rules and constraints are considered in a modular system aiming for configurable products. Partly configurable product structures differ from configurable product structures in that the former includes delivery-specific elements while the latter is based on the fact that the order-delivery process does not involve delivery specific engineering, but only selections based on predefined options. In relation to this, the previously presented definitions by Pahl and Beitz (2013) and Pakkanen et al. (2016, 2019) are incomplete when it comes to a partly configurable modular systems. However, it is also stated by Pahl and Beitz (2013) that the product can also include non-modules which reflect customer-specific requirements and are developed separately, but those are considered outside the modular system. This is similar definition as made by Borowski (1961) decades earlier. He presents that non-constructional elements are non-standardised elements that remain outside the system made of constructional elements whereas constructional elements are undivided entities within the system, which have a continuous interface in a physical or other sense. Therefore, the set of non-modules should also be considered as one of the key elements when considering development and management of a partly configurable modular system.

\subsection{Summary of literature - managing partly configurable modular systems}

Modularisation and configuration based on standard elements is well known in the literature, but the situation changes when the product is not "purely" configurable but contains partitions to be developed on a delivery-specific engineering basis. Product management has been discussed in several publications, but little specific management support has been presented for managing partly configurable modular systems.

\section{METHODOLOGY}

The research question was first clarified by describing the various topics related to the phenomenon with the help of the literature. In this article, we study previous product development cases in the manufacturing industry. Due to the limited literature on managing partly configurable modular systems, the scope is extended to other cases where modularisation and configuration were not a key part of the project objectives. The selection criteria of projects to be considered was that they have a clear link to managerial activities and the authors have been involved in the projects either as researchers or in the role of supervisors. Some of the projects (Sections 4.1 and 4.3) involved previous publications, but one of the projects presented in Section 4.2 did not have previous publications. The basic information about the projects is explained in this article and what the projects aimed for when they were active. This was followed by a retrospective discussion with those researchers or supervisors involved in the projects about what the results were and what their significance for managing partly configurable modular systems would be in line with the lessons learnt principle. For its part, the answer to the research question concluded in Section 6 forms hypotheses for more detailed research in the future.

\section{CASE STUdies}

This section presents three case studies. All represent different companies in the manufacturing industry. 
In all cases, structures with standard sections, alternative standard structures and delivery-specific "oneoff" sections could be identified from the related products, although at the time of the case study the core content of the projects was not related to modularisation or development of configurability. However, the cases related to product and product portfolio / product variety management tasks, which were presented in Section 2. The focus is on the selection of technology, the selection of concept, and describing the information flow of the product design and delivery process. Each case is presented and followed by a discussion of what could be learned from each case from the perspective of our RQ.

\subsection{Evaluating technology value}

The first case study focused on the modelling of the current product understanding into visual cause-andeffect models and using the model to evaluate the potential of new technologies regarding the existing product portfolio. In other words, the challenge was to briefly assess whether it is worthwhile to utilise a certain technology in business. The case was performed in a global original equipment manufacturer in the mining business. This case has been discussed in more detail in an article by Mämmelä et al. (2019). Olesen's (1992) definition of disposition was used as the theoretical background for understanding the effects of decisions in the manufacturing industry: part of a decision taken within one functional area affects the type, content, efficiency or progress of activities within other functional areas. Figure 1 presents the design reasoning pattern (DRP) created in the case. The description was made through several meetings, workshops, and semi-structured interviews. At the beginning of the project, the main goals were defined from the perspective of sustainable development: safety (from the overall perspective of society), profitability and consideration for the environment. The project also described the expected behaviour of the product. This included drilling speed and hole straightness. In addition to this, it was clarified what the connection of these behaviours was to the business in terms of money. Behaviours that incur costs were also considered. The costs were related to energy consumption and drill wear. The criteria for cost impact were discussed in a workshop that described the key elements and dependencies of the business environment using the Company Strategic Landscape (CSL) framework (Lehtonen, 2007). In the middle of Figure 1, the structural properties of the product were presented. Red arrows between elements depicted dispositions.

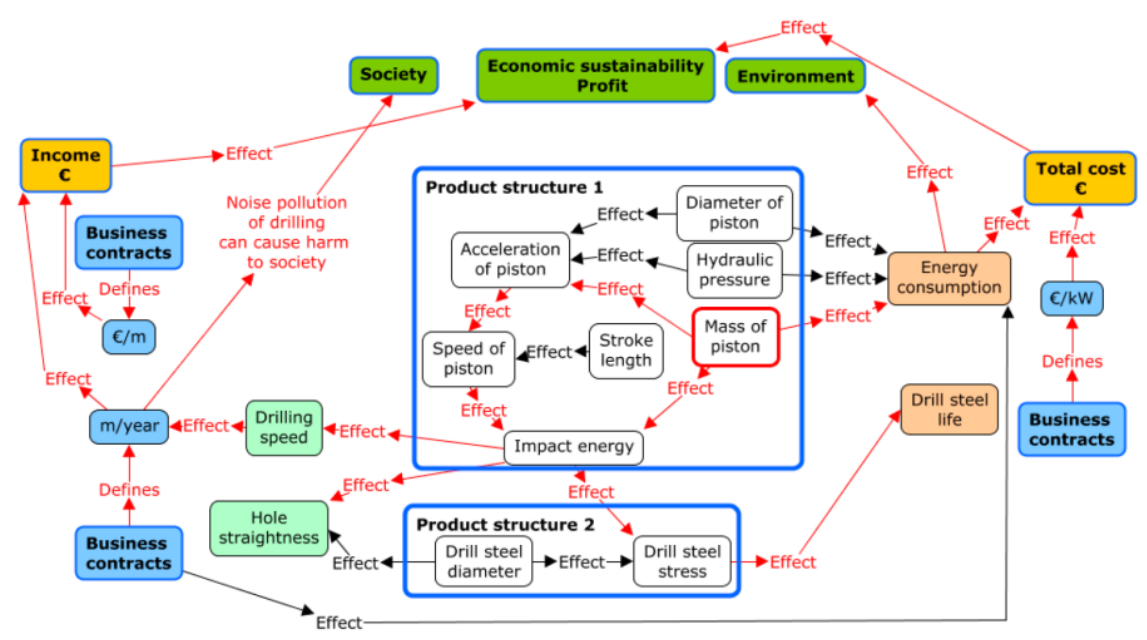

Figure 1.Design reasoning pattern (Mämmelä et al., 2019)

The modelled DRP diagram was utilised to evaluate the potential of the new technology. This was done first with the designers and then with the technology experts. Explicit reasoning description facilitated the evaluation. The goal was to capture estimates in money related to dispositions. In this case, the effects of the new technology, measured in monetary terms, were linked to product price, sales, design and management in delivery projects, business contracts, documentation, procurement and manufacturing. Many things were used in the assessment such as accounting data, knowledge about business contracts, knowledge about the effects on product lifecycle processes, shared understanding, and common agreement regarding the potential and business effect of technology. The evaluation method supported technology decision making. The method gathered knowledge about the business and product properties. This supported the understanding of technology and how different elements potentially create value for the company. From the point of view of modularisation, this approach is 
close to the business impact analysis discussed by, for example, Fixson (2006) and Pakkanen (2015), based on different modularisation impact mechanisms and how these are linked to, for example, interfaces and architectural choices. As Mämmelä et al. (2019) also note, such explicit case-specific models allow for many advantages such as that once the information is documented and everyone understands it in the same way, corrections and changes to the knowledge description are easier to make. The challenge in making such models is that the method relies heavily on workshops and facilitator skills, and agreeing on the shared vision can be challenging.

\subsection{Mapping product concept properties and production concept properties}

The second case study was part of a larger development project in a manufacturing company that was planning to renew existing production facility for a new production concept. Researchers participated in this project in 2015. In the project, the role of the researchers was to describe the current production flow and to perform a root cause analysis of the factors that make production control unpredictable and cause prolonging assembly lead times and uneven production flow. The project included drafting a systematic production planning process including risk analysis and preparing a target state description of the new plant's production. The interrelationships and effects of product concepts and production concepts were described explicitly including all work phases and their duration estimates. Cause-and-effect diagrams were used to assess the connections between product concepts and production concepts. Figure 2 shows an overview of such a model done in this case study blurred to respect the business confidential elements.

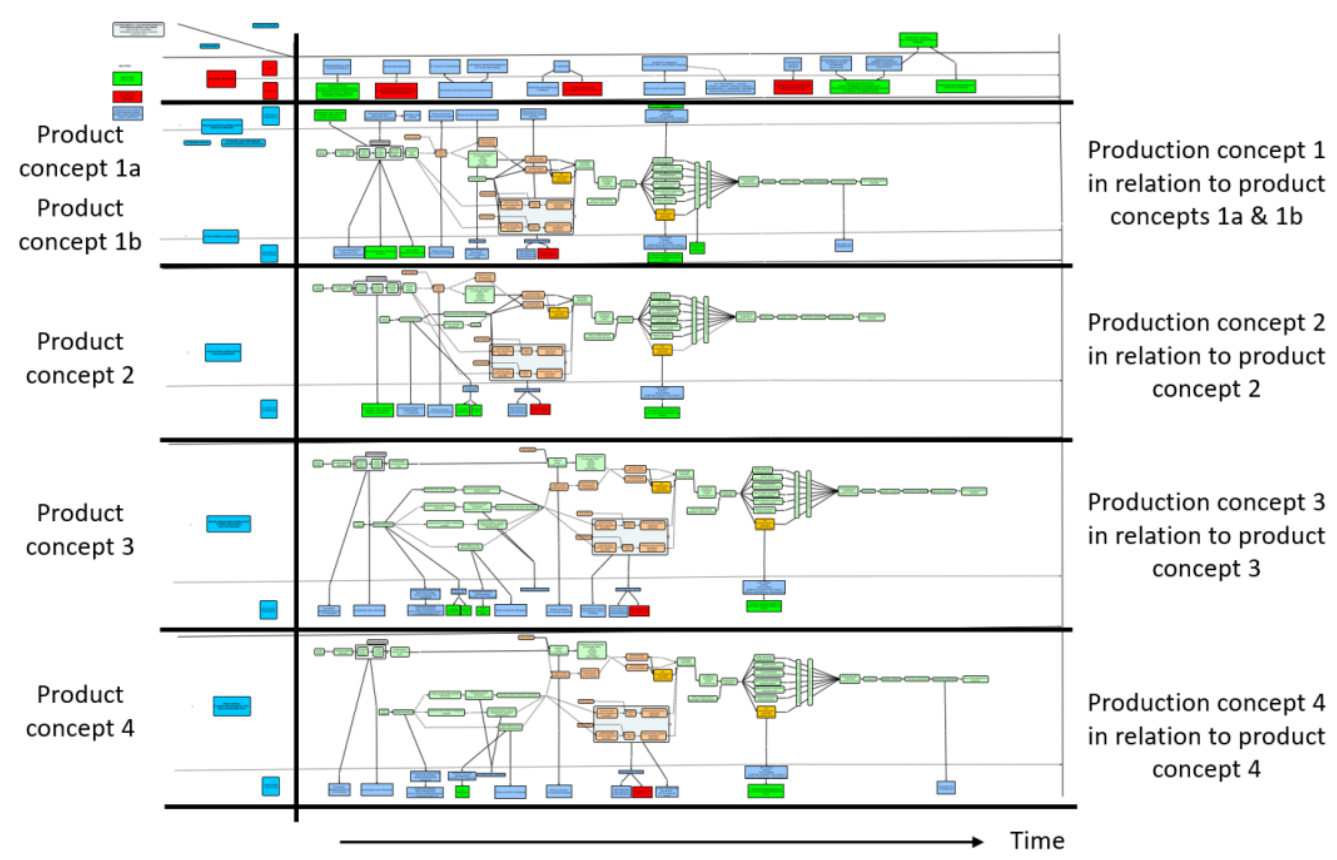

Figure 2. Mapping of relations between alternative product and production concepts

The rows in Figure 2 included analysis of alternative concepts related to a specific part of the product. The impact of these concepts on production was assessed. The top row described the current solution and a description of what production steps and production equipment are involved in its delivery chain. For example, the initial situation of the chain was that "the steel plates are on a roll" and the final situation on the right-hand side was that "the product system is in use by the customer". In between, all the steps required to achieve the final situation are described. Each concept was evaluated in relation to the description of the current state. For example, issues were raised regarding what are the critical relations in the different concepts and what requirements the alternative concepts place on the current production system and delivery chain phases and what are the effects (positive and negative effects or open issues that could not be assessed at the concept stage). As can be seen from Figure 2, certain elements remained the same in the rows of different concepts. This meant that they are not affected in any way by the properties of the concept. How the principles utilised in this case study example could be linked to modularisation? The approach used in the presented case guided the evaluation of the properties of the product concept in terms of the stages related to the supply chain. In brownfield cases, where the 
limitations of the existing environment must be taken into account, this is also important in the case of modular product concepts. In a previous research, for example, CSL framework (Lehtonen, 2007) is presented to emphasise that there is always a certain delivery chain structure against a particular product structure that allows for the greatest benefits. Thus, also in modularisation, it may be useful to analyse different module concepts or change requests by building a similar explicit cause-and-effect diagram of the current state as a baseline. This case study focused on how the product delivery flow changes as the product properties change. The product concept was not locked, but there were different scenarios in the review and where these leads. The same principles as in the property driven development presented by Weber and Deubel (2003) could be seen here; different properties produce a different behaviour and thus a different flow. The evaluation tool according to Figure 2 helped, for example, to cut micromanagement away from insignificant things. In a modular system management, such an approach could be applied in brownfield cases, for example, in comparing alternative module partitioning types for steps of the sales-delivery chain. From the point of view of modular system partitioning logic, it must be justified why a particular module division is followed (e.g. because it serves the sales-delivery chain). The review using the tool could explicitly highlight, for example, how the delivery-specific partitions in the different concepts fit into the current delivery chain. Thus, from a product management perspective, this tool provides a holistic view to the delivery chain to estimate change impacts.

\subsection{Mapping design decision sequence}

The third case focused on the early stages of new product development (NPD) projects in a multidisciplinary organisation, which sometimes has to rely on incomplete information, time is limited and concurrent engineering principles are used. The case related to cooperation of university with a forest machinery company and the case has been described in more detail in a previous article (Halonen et al., 2014). In the case, an answer was sought as to how the previous and existing understanding of the product development process could be utilised in overcoming the challenges at the fuzzy front end of product development projects. Challenges were approached by developing and testing a method that focused on design decision sequence. It was examined how the multidisciplinary sequence of design decisions can be explicitly described. The hypothesis was that describing the sequence of design decisions using an explicitly facilitated method and shared understanding would enable many benefits. The benefits were seen in better outcomes in NPD projects, improved semantics, improved individual ability to manage larger entities, new holistic and systemic knowledge, and improved reuse of design knowledge. The creation of a product structure-based information flow description was based on five steps. First, the individual design elements of the product were identified. Then, a) the generic engineering bill of materials, b) its sub-deliverables, and c) the sequence of design decisions were described in parallel taking into account the requirements, rules and design routines, product life cycle, and solutions of technical systems. Preparing design decision sequence diagram was based on the analysis of various design output documents, semi-structured interviews and workshops, and participant observation through site visits. These three models $(\mathrm{a}, \mathrm{b}$, and $\mathrm{c})$ were combined into the single model. The model described knowledge of the design process. Finally, maturity information of design elements was added to the model. This information was related to how complete the design of each particular element was. The research project ended here. After this, the model was ready to be applied and updated. The described design decision sequence diagram had a total of 197 elements. Figure 3 shows an overall view of the diagram. Because of business confidential aspects, details are not presented. The described design decision sequence diagram had a total of 197 elements. Although the central focus of the case company's product development was not on modularisation, 16 elements appeared in the model depicting the main technical interfaces of the product that were central to the interconnection of other components. In applying the method of describing design decisions, it was found that the holistic and systematic view of the product increased with the leader of the product development project. In addition, it was found that critical relationships between different design elements could be observed at an earlier stage. It was discussed that learning design process knowledge is easier when there is an explicit visual model as a mediating artefact. Compared to the previous case study, in this case a certain concept was already locked at the beginning of the project. One of the main tasks of this case was to identify the generic elements (the largest orange elements in Figure 3) that describe typical elements of a product type. The generic elements were independently designed entities. Identifying and describing this kind of division facilitated model making and structuring in the workshops. In modularisation, the technical structure is designed taking into account the variety requirements that are aimed to be encapsulated in the 
modules. In this case, you need to understand how decision-making takes place in the product. The flow model according to Figure 3 illustrates an example of the decision sequence of design elements. Thus, it is a model for the implementation of one specific product.

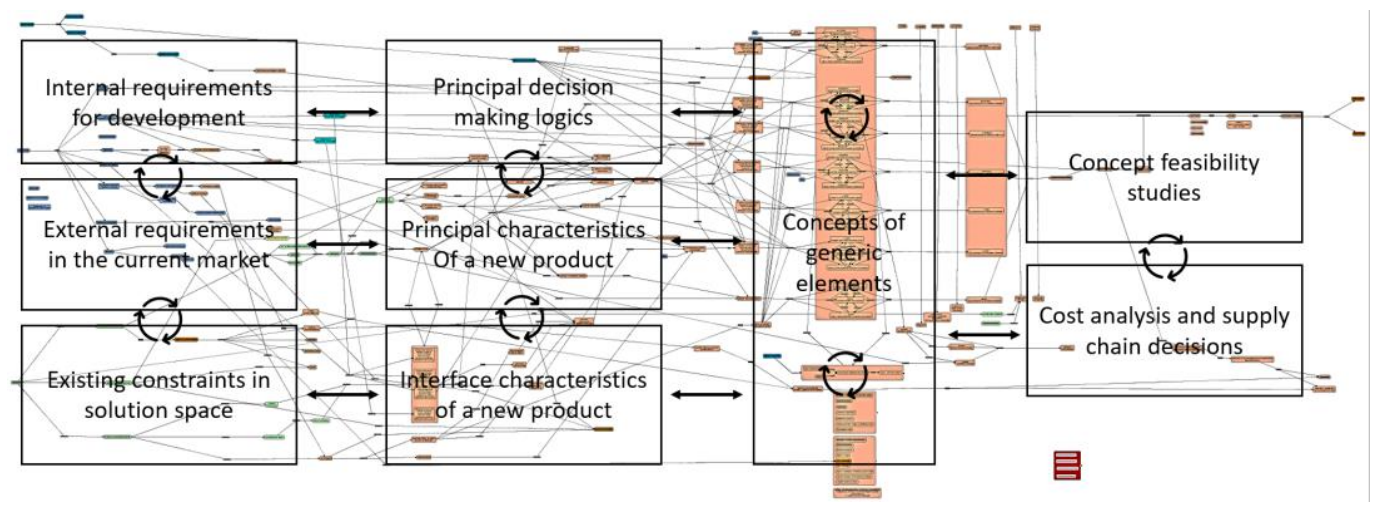

Figure 3. Design decision sequence diagram. Extended from Halonen et al. (2014)

\section{DIscussion}

Three case studies with a different resolution level for modelling design information were presented. In the first case, the starting point was the choice of technology. A cause-and-effect diagram was used to search for an answer to how product optimisation should take place in terms of decision-making. That is, how to evaluate the value of the new technology. Value-based development has been utilized in many areas, such as space propulsion technology (Panarotto et al. (2020). Our case is most distant from typical modularisation from all of the three cases, as modularisation is typically already further away from technology selection. In the second case, concept alternatives were studied. The flow model was used to identify a good solution. In the third case, the product concept was locked. The focus was to make a model that will facilitate the development and management of a good product repetitively. Modularisation requires an understanding of product creation process and design decision order. In managing a partly configurable modular system, it is important to understand which things have been locked and in what order. The description of the third case supports, for example, the transition to a systematic ETO approach. In addition, an understanding of design element entities and their dependencies also allows for paradigm jumping from ETO to configuration-based operations and thereby utilising the principles of modularity. If a partly configurable modular system is made sensibly, there must be a systematic understanding of the design revealing the design decision sequence. The flow model in the case study presented last also included design rules related to what design element dictates what, but also how things are attached to each other. Interface thinking is an important starting point in the direction of modularisation and configuration. Models like these can increase insights into product decision impacts that support stronger fact-based decision making in managerial tasks. Therefore, this research forms unique contribution to modular system management by extending the management to partly configurable products with visual modelling of design information and knowledge. As the main contribution, we link previous product information models of earlier case studies to the discussion of what could be learned from these in the context of modularization. Thus, as an answer to RQ, we suggest that the management of a partially configurable modular system is supported by an understanding of the product development process, an understanding of the order in which design decisions are made, and an understanding of the dependencies of design elements. Similar dependency models presented in Section 4 have been made, for example, in the aerospace industry (Frankenberger, 2007), but in those the perspective has been more in the installation phase.

\section{CONCLUSIONS}

The aim of the paper was to study how to support the management of a partly configurable modular system. The study looked at non-modularisation projects in which visual cause-and-effect and information and task flow models were developed and used to support product development and management. These models have been used in describing design rationale and the flow of design information from the perspective of data elements and design decisions. A preliminary indication of the 
benefits of applying these kinds of models can be seen from the perspective of management, e.g. in situations where the impact of a change proposal or change pressure has to be assessed from the perspective of different hierarchy levels of the product portfolio elements, order-delivery process, and product lifecycle including supply chain. However, there is not yet much experience with such models in the partly configurable modular system context, so further research is needed to elucidate the benefits and challenges of these tools. The concept of "non-modules" was discussed in literature section. This would involve enabling craft solutions, while respecting the restrictions of the modular system. Restrictions could relate, for example, to space reservations, interfaces and recommended product structuring principles from the perspective of the business environment. Thus, rules that come from the product idea could be also set for non-modules. In order to manage these, the rational must be described, for example, by means of an information flow model. By taking these into account successfully, systematic engineering to order approach could be enabled alongside the configuration.

\section{REFERENCES}

Andreasen, M.M. (2011), “45 Years with design methodology”, Journal of Engineering Design, Vol. 22 No. 5 , pp. 293-332.

Borgue, O., Panarotto, M. and Isaksson, O. (2019), "Modular product design for additive manufacturing of satellite components: maximising product value using genetic algorithms", Concurrent Engineering Research and Applications, Vol. 27 No. 4, pp. 331-346.

Borowski, K.-H. (1961), Das Baukastensystem in Der Technik, Springer-Verlag, Berlin Heidelberg.

Brown, D.C. (1998), "Defining configuring”, Artificial Intelligence for Engineering Design, Analysis and Manufacturing: AIEDAM, Vol. 12 No. 4, pp. 301-305.

Bruun, H.P.L., Mortensen, N.H. and Harlou, U. (2013), "PLM Support for Development of Modular Product Families", Proceedings of International Conference on Engineering Design, ICED13, Aug 19-22, 2013. Sungkyunkwan University, Seoul, Korea.

Cai, Y.L., Nee, A.Y.C. and Lu, W.-F. (2009), “Optimal Design of Hierarchic Components Platform under Hybrid Modular Architecture", Concurrent Engineering, Vol. 17, pp. 267-277.

Cooper, R., Edgett, S. and Kleinschmidt, E. (2001), "Portfolio management for new product development: Results of an industry practices study”, R and D Management, Vol. 31 No. 4, pp. 361-380.

ElMaraghy, H., Schuh, G., Elmaraghy, W.H., Piller, F.T., Schönsleben, P., Tseng, M. and Bernard, A. (2013), "Product variety management", CIRP Annals - Manufacturing Technology, CIRP, Vol. 62 No. 2, pp. 629-652.

Fixson, S.K. (2006), “A Roadmap for Product Architecture Costing”, in Simpson, T.W., Siddique, Z. \& Jiao, R.J. (Ed.), Product Platform and Product Family Design, Springer Science+Business Media, LLC, New York, pp. 305-334.

Forza, C. and Salvador, F. (2008), “Application support to product variety management”, International Journal of Production Research, Taylor \& Francis Group, Vol. 46 No. 3, pp. 817-836.

Frankenberger, E. (2007), "Concurrent design and realization of aircraft production flow lines - Process challenges and successful design methods", Proceedings of ICED 2007, the 16th International Conference on Engineering Design, Vol. DS 42, The Design Society, pp. 1-11.

Fujimoto, T. (2007), Competing to Be Really, Really Good - The behind-the-Scenes Drama of Capability Building Competition in the Automobile Industry, International House of Japan, Tokyo.

Gedell, S. and Johannesson, H. (2013), "Design rationale and system description aspects in product platform design: Focusing reuse in the design lifecycle phase", Concurrent Engineering Research and Applications, Vol. 21 No. 1, pp. 39-53.

Gorchels, L. (2003), "Transitioning from engineering to product management”, EMJ - Engineering Management Journal, Vol. 15 No. 4, pp. 40-47.

Halonen, N., Lehtonen, T. and Juuti, T. (2014), "Impacts of making design decision sequence explicit on NPD project in forest machinery company”, in Laakso, M. and Ekman, K. (Eds.), DS 81: Proceedings of NordDesign 2014, Espoo, Finland 27-29th August 2014, The Design Society, pp. 702-711.

Haug, A. (2008), Representation of Industrial Knowledge - as a Basis for Developing and Maintaining Product Configurators, Technical University of Denmark.

Jugend, D. and Da Silva, S.L. (2014), "Product-portfolio management: A framework based on methods, organization, and strategy", Concurrent Engineering Research and Applications, Vol. 22 No. 1, pp. 17-28.

Juuti, T. (2008), Design Management of Products with Variability and Commonality - Contribution to the Design Science by Elaborating the Fit Needed between Product Structure, Design Process, Design Goals, and Design Organisation for Improved R\&D Efficiency, Tampere University of Technology.

Juuti, T. and Lehtonen, T. (2006), "Using Multiple Modular Structures in Delivering Complex Products", Proceedings of NordDesign, pp. 266-276. 
Kazemzadeh, R.B., Behzadian, M., Aghdasi, M. and Albadvi, A. (2008), "Integration of marketing research techniques into house of quality and product family design", The International Journal of Advanced Manufacturing Technology, Vol. 41 No. 9-10, pp. 1019-1033.

Kristjansson, A.H., Jensen, T. and Hildre, H.P. (2004), "The term platform in the context of a product developing company", in Marjanovic, D. (Ed.), Proceedings of DESIGN 2004, the 8th International Design Conference, Dubrovnik, Croatia, pp. 325-330.

Lehtonen, T. (2007), Designing Modular Product Architecture in the New Product Development, Tampere University of Technology, Tampere.

Lehtonen, T., Juuti, T., Pulkkinen, A. and Riitahuhta, A. (2003), "Dynamic Modularisation - A challenge for design process and product architecture", Proceedings of International Conference on Engineering Design, ICED 03, Stockholm.

Maglyas, A., Nikula, U. and Smolander, K. (2012), "What do practitioners mean when they talk about product management?”, 2012 20th IEEE International Requirements Engineering Conference, RE 2012 - Proceedings, IEEE, pp. 261-266.

Mämmelä, J., Juuti, T. and Julkunen, P. (2019), "Technology Valuation Method for Supporting Knowledge Management in Technology Decisions to Gain Sustainability”, Sustainability, MDPI AG, Vol. 11 No. 12, p. 3410.

McNally, R.C., Durmusoglu, S.S., Calantone, R.J. and Harmancioglu, N. (2009), "Exploring new product portfolio management decisions: The role of managers' dispositional traits”, Industrial Marketing Management, Elsevier Inc., Vol. 38 No. 1, pp. 127-143.

Meyer, M.H. and Lehnerd, A.P. (1997), The Power of Product Platforms: Building Value and Cost Leadershop, The Free Press, New York.

Murphy, W.H. and Gorchels, L. (1996), "How to improve product management effectiveness”, Industrial Marketing Management, Vol. 25 No. 1, pp. 47-58.

Olesen, J. (1992), Concurrent Development in Manufacturing - Based on Dispositional Mechanisms, Institute for Engineering Design, The Technical University of Denmark.

Pahl, G. and Beitz, W. (2013), Engineering Design: A Systematic Approach, Vol. 11, Springer Science \& Business Media.

Pakkanen, J. (2015), Brownfield Process: A Method for the Rationalisation of Existing Product Variety towards a Modular Product Family, Tampere University of Technology.

Pakkanen, J., Juuti, T. and Lehtonen, T. (2016), "Brownfield Process: A method for modular product family development aiming for product configuration”, Design Studies, Elsevier Ltd, Vol. 45, pp. 210-241.

Pakkanen, J., Juuti, T. and Lehtonen, T. (2019), "Identifying and addressing challenges in the engineering design of modular systems - case studies in the manufacturing industry", Journal of Engineering Design, Vol. 30 No. 1, pp. 32-61.

Panarotto, M., Isaksson, O., Habbassi, I. and Cornu, N. (2020), "Value-Based Development Connecting Engineering and Business: A Case on Electric Space Propulsion", IEEE Transactions on Engineering Management, pp. 1-14.

Pulkkinen, A. (2007), Product Configuration in Projecting Company: The Meeting of Configurable Product Families and Sales-Delivery Process, Tampere University of Technology.

Roach, D.C. (2011), "The impact of product management on SME performance: Evidence from Canadian firms", Journal of Small Business and Enterprise Development, Vol. 18 No. 4, pp. 695-714.

Sosa, M.E., Eppinger, S.D. and Rowles, C.M. (2007), "A network approach to define modularity of components in complex products", Journal of Mechanical Design, Vol. 129 No. November 2007, pp. 1118-1129.

Tiihonen, J., Lehtonen, T., Soininen, T., Pulkkinen, A., Sulonen, R. and Riitahuhta, A. (1999), "Modelling configurable product families", Proceedings of the 12th International Conference on Engineering Design, ICED99, Vol 2, Munich, Germany.

Tolonen, A., Shahmarichatghieh, M., Harkonen, J. and Haapasalo, H. (2015), "Product portfolio management Targets and key performance indicators for product portfolio renewal over life cycle", International Journal of Production Economics, Vol. 170, pp. 468-477.

Ulonska, S. and Welo, T. (2014), "Product portfolio map: A visual tool for supporting product variant discovery and structuring", Advances in Manufacturing, Vol. 2 No. 2, pp. 179-191.

Ulrich, K.T. and Eppinger, S.D. (2008), Product Design and Development, McGraw-Hill, New York.

Um, J., Lyons, A., Lam, H.K.S., Cheng, T.C.E. and Dominguez-Pery, C. (2017), "Product variety management and supply chain performance: A capability perspective on their relationships and competitiveness implications", International Journal of Production Economics, Elsevier B.V., Vol. 187 No. June 2016, pp. 15-26.

Vähäniitty, J. (2003), "Key decisions in strategic new product development for small software product businesses", 2003 Proceedings 29th Euromicro Conference, IEEE, Belek-Antalya, Turkey, pp. 375-383.

Weber, C. and Deubel, T. (2003), "New Theory-Based Concepts for Pdm and Plm”, ICED 03, Stockholm, pp. $1-10$.

Winterkorn, M. and Pötsch, H.D. (2012), “Volkswagen Golf VII: Launch of a new era”, Sardinia. 